\title{
Correction to: Non-participation and Heterogeneity in Stated Preferences: A Double Hurdle Latent Class Approach for Climate Change Adaptation Plans and Ecosystem Services
}

\author{
Zhenshan Chen $^{1}$ (D) . Stephen K. Swallow ${ }^{2} \cdot \operatorname{Ian}$ T. Yue
}

Published online: 15 September 2020

(c) Springer Nature B.V. 2020

\section{Correction to: Environmental and Resource Economics (2020) 77:35-67 https://doi.org/10.1007/s10640-020-00434-z}

The article was published with a typographical error in the title. The title should be cited and referenced as, Non-participation and Heterogeneity in Stated Preferences: A double hurdle latent class approach for climate change adaptation plans and ecosystem services, and not the prior.

This correction stands to correct the original article.

Publisher's Note Springer Nature remains neutral with regard to jurisdictional claims in published maps and institutional affiliations.

The original article can be found online at https://doi.org/10.1007/s10640-020-00434-z.

Zhenshan Chen

zhenshan.chen@uconn.edu

1 Department of Agricultural and Resource Economics, University of Connecticut, 1376 Storrs Road Unit 4021, Storrs, CT, USA

2 Department of Agricultural and Resource Economics and Center for Environmental Sciences and Engineering, University of Connecticut, 1376 Storrs Road Unit 4021, Storrs, CT, USA

3 Division of Climate, Coastal, and Energy, Delaware Department of Natural Resources and Environmental Control, 100 W. Water Street, Suite 5A, Dover, DE, USA 